\title{
Development of a Temperature-Dependent Growth Model for the Endangered Humpback Chub Using Capture-Recapture Data
}

\author{
Lewis G. Coggins, Jr. ${ }^{1, *}$ and William E. Pine, $\mathrm{III}^{2}$ \\ ${ }^{1}$ U.S. Geological Survey, Grand Canyon Monitoring and Research Center, Flagstaff, AZ 86001, USA \\ ${ }^{2}$ Fisheries and Aquatic Sciences Program, School of Forest Resources and Conservation and Department of Wildlife \\ Ecology and Conservation, University of Florida, Gainesville, FL 32653, USA
}

\begin{abstract}
Model derived predictions of fish growth are frequently required for detailed investigations of population dynamics to inform management decisions. Simple growth models are typically fit to paired age and length data, but age data is often not available from endangered species because of restrictions on lethal or invasive sampling methods. Growth increment data from capture-recapture studies can be used to inform such models, but currently available methods to fit data to growth models may produce biased predictions when growth is variable among individual fish, or when growth rate varies non-linearly with fish size. This study used a recently proposed growth model derived from basic bioenergetic principals to estimate growth of humpback chub in Grand Canyon, Arizona. The modeling framework allows incorporation of temperature-dependent shifts in growth rate associated with both seasonal variability in water temperature and ontogenetic migrations between the seasonally warm Little Colorado River and the constantly cold Colorado River. Results indicate that consideration of temperature-dependent shifts in growth rate are critical to accurately describe the growth of humpback chub, and that management actions aimed at increasing water temperature in the thermally modified Colorado River could aid the recovery of this species by increasing growth rate and survivorship.
\end{abstract}

Keywords: Colorado River, humpback chub, endangered species, bioenergetics, capture-recapture.

\section{INTRODUCTION}

A primary interest of fisheries biologists is to estimate rates of fish growth and understand the processes and factors that influence growth. Such information is critical for research addressing questions about basic ecological relationships and for managing fisheries. In the latter case, growth information is frequently used to populate assessment models with vital rates [1-3] and age-specific length, weight, fecundity, and vulnerability to exploitation [4]. Additionally, information on growth may be used to estimate the age of fish based on size [5]. Given the importance of understanding growth, much effort has been expended to understand factors that influence growth, to develop models to describe observed growth patterns, and to estimate the parameters of those models $[6,7]$.

The federally endangered cyprinid humpback chub Gila cypha is endemic to the Colorado River drainage in the southwestern United States and is generally found in swift, canyon bound river reaches [8]. Periodic stock assessments of this population serve as the core monitoring tool to determine the status for this resource. These assessments require accurate age assignments of fish captured in a long-term sampling program [9] in order to employ open population mark-recapture assessment methods that include agedependent effects. Due to endangered species listing status

*Address correspondence to this author at the U.S. Geological Survey, Grand Canyon Monitoring and Research Center, Flagstaff, AZ 86001, USA; Tel: 928-556-7634; Fax: 928-556-1709; E-mail: lcoggins@usgs.gov and associated restrictions on lethal or invasive sampling methods, little information is available on longevity and the relationship between size and age for this species. At present, individual age assignments are based on size and rely on a growth curve estimated from a limited set $(\mathrm{n} \approx 60)$ of age-length observations [10]. This lack of growth information promotes uncertainty and possibly bias in length-based age assignment, and this potential bias has been identified as an area of concern by past external reviews of the humpback chub assessment program [11].

We used growth increment data to estimate the parameters of a generalized growth model described by Walters and Essington [12] for the Little Colorado River (LCR) population of humpback chub within Grand Canyon. This effort was undertaken to supplement the available information on humpback chub growth and to inform length-based age assignments for stock assessments. Because the older fish in this population exhibit a potadromous migration between the seasonally warm LCR and the constant cold mainstem Colorado River [13], we evaluated ontogenetic temperaturedependent effects in the growth model. The resulting temperature-dependent growth model is also useful to river managers considering implications for humpback growth and survival under various management options designed to increase water temperature in the thermally-modified Colorado River in Grand Canyon.

\section{METHODS}

An extensive monitoring program for the LCR population of humpback chub has been ongoing since the late 


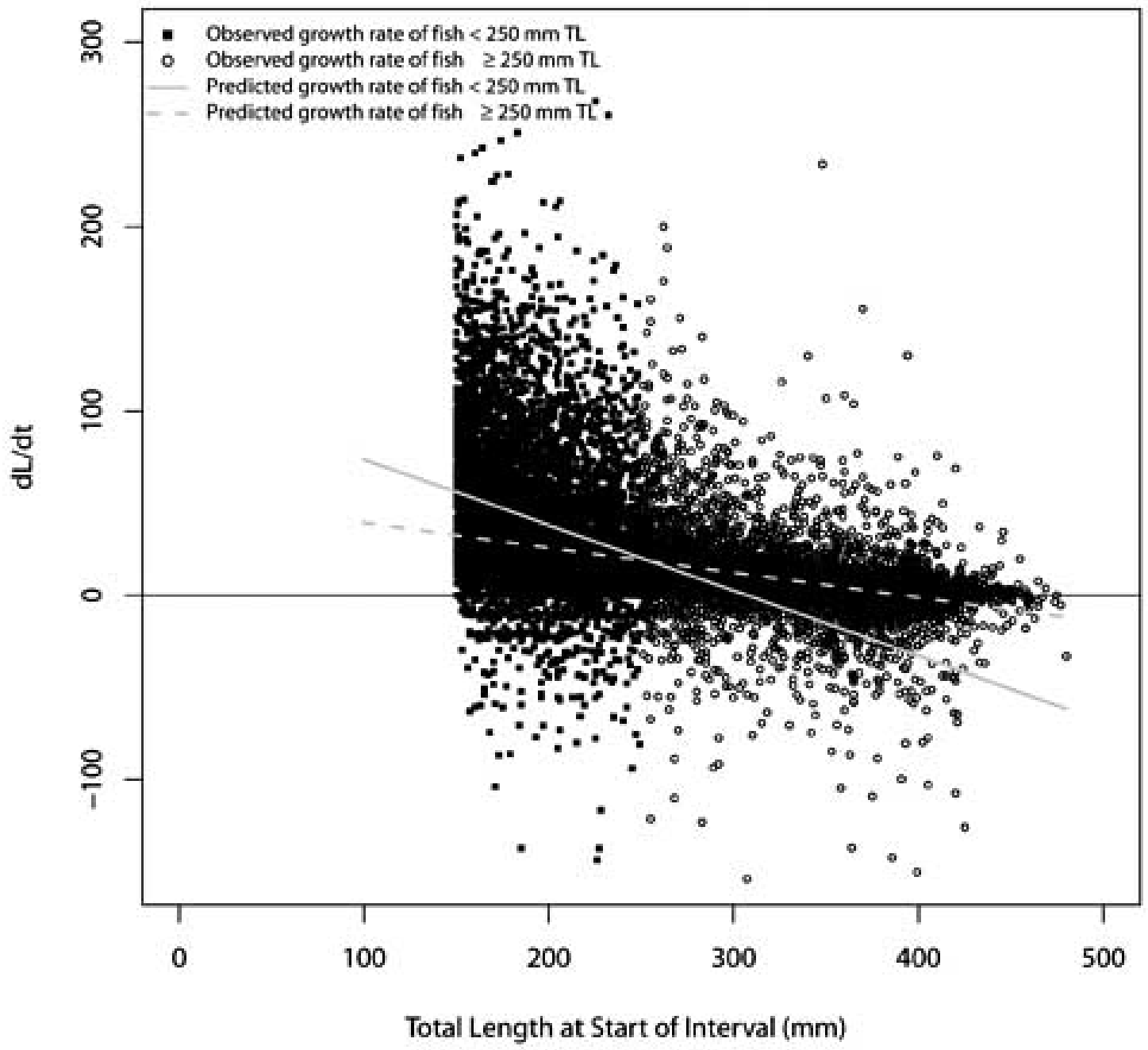

Fig. (1). Observed and predicted humpback chub growth rate (dL/dt) as a function of total length (mm). Solid squares are observed growth rate of fish initially captured with TL $<250 \mathrm{~mm}$ and open circles are observed growth rate of fish initially captured with TL $\geq 250 \mathrm{~mm}$. Predicted growth rates are simple linear regressions on observed growth rate of fish initially captured with TL $<250 \mathrm{~mm}$ (solid line) and of fish initially captured with $\mathrm{TL} \geq 250 \mathrm{~mm}$ (dashed line).

1980s [9]. A key component of this monitoring program is an extensive mark-recapture data base where humpback chub are captured, measured, marked with passive integrated transponder tags, and later recaptured. From this program we compiled nearly 15,000 growth increments with which to estimate bioenergetic parameters and evaluate growth rate using methods described by Walters and Essington [12]. The basic technique for estimating growth model parameters from growth increment data is to predict the amount of growth in the elapsed time between capture and recapture. Assuming standard von Bertalanffy growth curve predictions of length at time $t$ and at time $t+\Delta t$, Fabens [14] developed the most basic model where the predicted growth increment is given as:

$$
\Delta L=L(t+\Delta t)-L(t)=\left(L_{\infty}-L(t)\right)\left(1-e^{-k \Delta t}\right),
$$

where $t$ is time at initial capture, $\Delta t$ is the elapsed time between initial capture and recapture, and $L_{\infty}$ and $k$ are the asymptotic length and the rate at which length approaches
$L_{\infty}$, respectively [15]. Parameter estimates are found by minimizing the difference between predicted and observed growth increments.

The Fabens method is widely applied, but numerous authors have pointed out how resulting parameter estimates will be biased if individual fish exhibit growth variability [16-18]. Using this technique, the von Bertalanffy $k$ will typically be negatively biased and $L_{\infty}$ will be positively biased. Recognition of these problems motivated the development of alternative models to minimize these biases [19-21]. We attempted to estimate standard von Bertalanffy growth parameters for humpback chub using two of these methods $[20,21]$ and generally obtained poor results, characterized by an inability of the models to predict growth increments exhibited by small fish and large fish simultaneously (Fig. 1). Examination of growth rate as a function of size revealed that the basic problem with fitting a standard von Bertalannfy model to these data was the lack of a simple linear relationship between growth rate and length as implied by this 
model. It is apparent that the fish less than about $250 \mathrm{~mm}$ TL have a larger von Bertalanffy $k$ parameter value (i.e., more negative slope of the growth rate vs. length plot) than fish larger than $250 \mathrm{~mm}$ TL. These results suggest a "kink" in the growth curve as would be found if fish grew along one curve when small and then switched to another when larger.

Water temperature is a major determinant of basal metabolic rate, and hence the von Bertalanffy $k$ parameter, among poikilotherms $[22,23]$. Our "kink" hypothesis in growth rate is consistent with observations of humpback chub demonstrating an ontogenetic shift among habitats that have different water temperatures. In our study area, this shift is a transition from the warm LCR spawning and rearing habitat to the cooler mainstem Colorado River adult habitat [13, 24]. To account for these changing growth rates, we fit both the general and seasonal bioenergetic models for length dynamics described by Walters and Essington [12] to the humpback chub growth increment data. The basic derivation of the length dynamics models of Walters and Essington [12] begins with a description of the rate of change in body weight as:

$\frac{d W}{d t}=H W^{d}-m W^{n}$.

Here, the first term describes anabolism (i.e., mass acquisition) and is governed by a term representing the mass normalized rate at which the animal acquires mass $(H)$, the mass of the animal $(W)$, and a parameter $(d)$ describing the scaling of anabolism with mass. The second term represents catabolism (i.e., mass loss through basal metabolism or activity) where $m$ is the mass normalized rate at which the animal looses mass and $n$ is the scaling factor of catabolism with mass. Assuming a constant relationship between length and weight over time as:

$W=a L^{b}$,

where $L$ is length and $a$ and $b$ are constant, it is possible to derive an analogous relationship for the rate of change in length as

$\frac{d L}{d t}=\alpha L^{\delta}-\kappa L^{\eta}$.

Constants in this relationship are related to those in (2) and (3) as:

$\alpha=\frac{a^{d-1} H}{b}$,

$\kappa=\frac{a^{n-1} m}{b}$,

$\delta=b d-b+1$, and

$\eta=b n-b+1$

where $s$ is the number of growth increments, $\lambda$ is the weighting value for the penalty terms, $L(i)$ is the predicted length in month $i$ from the general model, and $\ell(i)$ is the predicted length over $m o s=32$ months as reported by Robinson and Childs [25].

The minimum length for tagging humpback chub in our mark-recapture database is $150 \mathrm{~mm}$ TL. This creates a problem for extrapolating results to smaller fish because of sparse observations of growth increments for fish below this minimum size. Fortunately, Robinson and Childs [25] conducted monthly sampling of juvenile humpback chub in the LCR during 1991-1994. They used these data to estimate (by modal progression analysis) average monthly length from age- 0 months to age-32 months. We used these mean monthly length estimates to constrain the predicted lengths from our Walters and Essington [12] models to be similar to those reported by Robinson and Childs [25]. Using these auxiliary data [25] allowed us to incorporate information on humpback chub growth rates for fish $<150 \mathrm{~mm}$ TL into our growth models. Additionally, we included penalty terms in the log-likelihood to constrain the scaling parameters $d$ and $n$ to be similar to the theoretical values assuming standard von Bertalanffy growth of $2 / 3$ and 1 , respectively. We evaluated alternative weight values on these penalty terms to find an appropriate tradeoff between minimum weights and decreased log-likelihood. With these constraints in place, the full log-likelihood is:

$$
\begin{gathered}
\ln L\left(\theta \mid L(t)_{i}, L(t+\Delta t)_{i}\right)=-\frac{s}{2} \sum_{i}^{s} \frac{D_{i}}{\sigma_{L(t+\Delta t) i}^{2}}-\frac{1}{2} \sum_{i}^{s} \sigma_{L(t+\Delta t) i}^{2} \\
-\frac{1}{2 \lambda}\left(d-\frac{2}{3}\right)^{2}-\frac{1}{2 \lambda}(n-1)^{2}-\frac{m o s}{2} \sum_{i=1}^{m o s} \ln \left(\frac{L(i)-\ell(i)}{\sigma_{\ell}}\right)^{2}
\end{gathered}
$$

where $s$ is the number of growth increments, $\lambda$ is the weighting value for the penalty terms, $L(i)$ is the predicted length in month $i$ from the general model, and $\ell(i)$ is the predicted length over $m o s=32$ months as reported by Robinson and Childs [25]. We specified the variance of the observed lengths $\sigma_{\ell}^{2}$ as unity. The weighting term can be interpreted as the prior variance on the standard von Bertalanffy parameters $(d=2 / 3$, and $n=1)$. Definitions of the remaining parameters can be found in Walters and Essington [12].

An important logical extension of the general model is to allow seasonal temperature dependence in growth rate as described by Walters and Essington [12]. Accounting for changes in growth rate as a function of temperature is likely to be important for the analysis of humpback chub growth for two reasons. The first is to account for the differences in growth rate with occupancy in either the LCR or the mainstem Colorado River. The second is to account for seasonal changes in water temperature within the LCR. The importance of the second consideration is further magnified by the temporal distribution of sampling within the LCR. Sampling in the LCR typically occurs in the spring and fall. Therefore, much of the observed growth increment data corresponds to either summer growth (i.e., observations of fish captured in spring and again in fall) or winter growth (i.e., observations of fish captured in fall and the following spring). Because 
growth rate varies with temperature [26], we expect growth increments to be smaller during winter than during summer. This general prediction is also consistent with both field [25] and laboratory [27] observations of humpback chub.

Following Walters and Essington [12], we defined temperature-dependent multipliers of the anabolic and catabolic scaling parameters $\alpha$ and $\kappa$ of the length dynamic model as

$\frac{d L}{d t}=\alpha L^{\delta} Q_{c}^{\frac{(T-10)}{10}}-\kappa L^{\eta} Q_{m}^{\frac{(T-10)}{10}}$.

The consumption and metabolism coefficients $\left(Q_{c}\right.$ and $Q_{m}$ ) of a Q10 relationship allow anabolism and catabolism to increase or decrease with temperature $(T)$.

To account for both differences in temperature between the LCR and the mainstem Colorado River and to predict occupancy in either location, we first used a logistic function to model occupancy in either the LCR or the mainstem Colorado River. We assumed that the probability of LCR occupancy is given as

$$
P L C R=1-\frac{0.8}{1+e^{-\frac{\left(L-L_{t}\right)}{20}},}
$$

where $L$ is fish total length and $L_{t}$ is the fish total length where the probability of residing in the LCR year round is 0.6 . The behavior of this model is such that the probability of year-round LCR residency approaches unity at lengths much less than $L_{t}$ and decreases to 0.2 at lengths much larger than $L_{t}$. The number 20 in the denominator of the exponent governs the rate at which the probability changes from near unity to near 0.2 . The asymptote at 0.2 requires at least some LCR residency for even the largest fish and is consistent with the observation that adult humpback chub use the LCR for spawning [13].

We then defined a weighted temperature function experienced by fish of a particular length as

$$
T(t)=(P L C R) T_{L C R}(t)+(1-P L C R) T_{M S}(t),
$$

where $T_{L C R}(t)$ is the time-dependent water temperature in the LCR and $T_{M S}(t)$ is the time-dependent water temperature in the mainstem Colorado River. This overall temperature experienced by a fish of a given length is then used in equation (10) to predict growth rate considering time-dependent changes in water temperature and size-dependent changes in LCR versus mainstem Colorado River occupancy.

To model the time-dependent water temperature in the LCR, we used data reported by Voichick and Wright [28] to predict average monthly water temperature considering data 1988-2005. We fit these data with a sine curve as:

$$
T_{L C R}(t)=T_{\text {ave }}+\left(T_{\max }-T_{\text {ave }}\right) \sin \left(2 \pi\left(t+t_{\text {peak }}\right)\right),
$$

where $t$ is time in fraction of a year starting April 1, $t_{\text {peak }}$ is a phase shift allowing predicted peak temperature to align temporally with the observed peak temperature, $T_{\text {ave }}$ is the $1 / 2$ amplitude temperature and roughly corresponds to the average annual temperature, and $T_{\max }$ is the maximum annual temperature. We estimated $t_{\text {peak }}, T_{\text {ave }}$, and $T_{\max }$ by minimizing the squared difference between observed and predicted monthly temperature.

Annual water temperature variation in the mainstem Colorado River near the confluence of the LCR is much less variable (range $8-12^{\circ} \mathrm{C}$; Fig. 2) than within the LCR [28]. Thus, we assumed constant water temperature in the mainstem Colorado River of $10^{\circ} \mathrm{C}$. This value corresponds roughly to the average water temperature within the LCR inflow reach of the Colorado River during much of the time when the growth increments were observed (1989-2006).

We fit both the general (hereafter termed the temperature-independent growth model, TIGM) and the seasonal (hereafter termed the temperature-dependent growth model, TDGM) bioenergetic models for length dynamics in both Microsoft Excel using Solver [29] and AD Model Builder [30] to obtain parameter estimates. For the TIGM we estimated the parameter vector $\theta=\left\{H, d, m, n, \sigma_{L}^{2}\right\}$. Walters and Essington [12] warn that the parameters of the TDGM are likely to be highly correlated and should be specified from auxiliary information if possible. Therefore, we reduced the parameter set by specifying the measurement error variance as $\sigma_{m}^{2}=31.8 \mathrm{~mm}^{2}$ based on an analysis of the observed error between consecutive measurements of identical fish within 10 days. For the more complex TDGM, we estimated the parameter vector $\theta=\left\{H, d, m, n, Q_{c}, L_{t}\right\}$. Following guidance from a meta-analysis by Clark and Johnson [31], we specified $Q_{m}$ as 2 to reduce the parameter set. To further reduce the parameter set, we specified $\sigma_{L}^{2}=2,000$ to correspond with a coefficient of variation of about $10 \%$ as is the maximum typically observed in fish populations [32]. We compared model fit for the temperature-independent growth model and the temperature-dependent growth model using AIC techniques [33].

With length-at-age predictions available from the TDGM for a given water temperature, it is possible to compare survivorship from age-1 to age-10 under various Colorado River water temperatures scenarios and assuming that mortality-at-age follows a Lorenzen [34] type relationship as:

$$
S 10=\prod_{a=1}^{9} \exp \left(-\frac{L_{\infty}}{L_{a}} M_{L_{\infty}}\right)
$$

where $a$ is age, S10 is the survivorship from age- 1 to age- 10 , $L_{a}$ is length-at-age, and $M_{L_{\infty}}$ is the mortality rate suffered by a fish of length $L_{\infty}$. We specified $M_{L_{\infty}}=0.14$ based on recent humpback chub stock assessments [35]. 


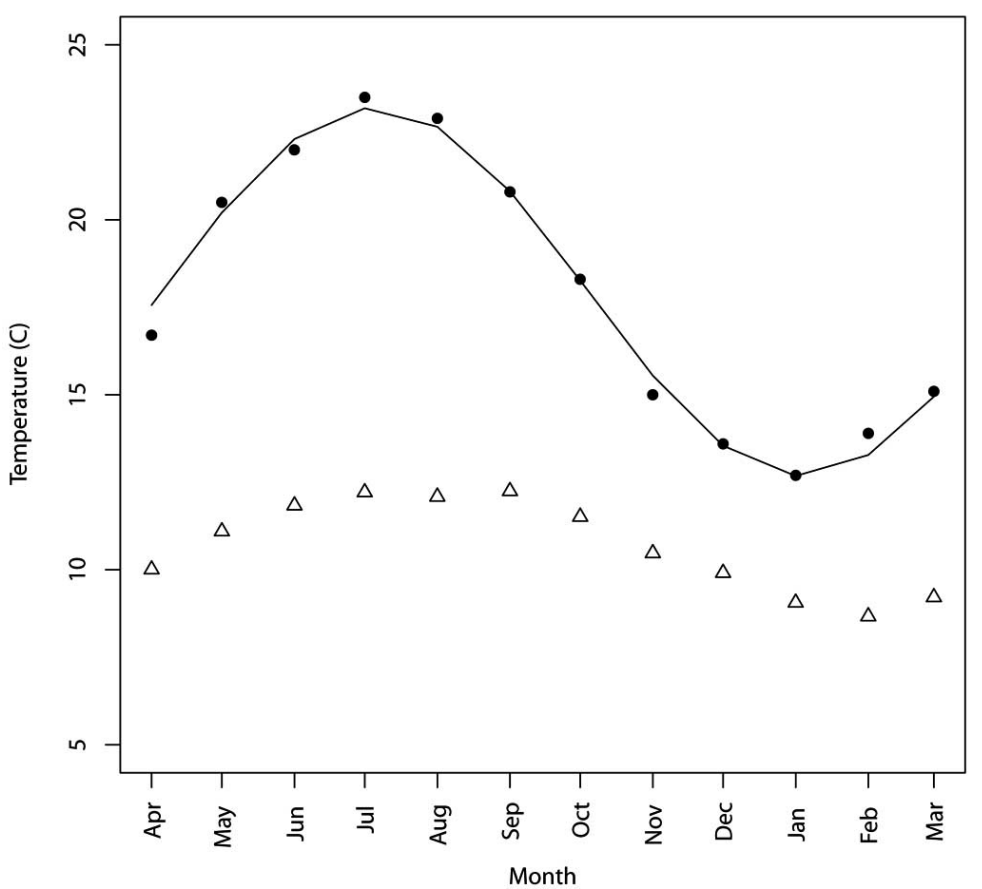

Fig. (2). Average monthly water temperatures in the Little Colorado River (solid circles) and average monthly water temperature in the Colorado River near the confluence with the Little Colorado River (open triangles). The line is the model predicted monthly water temperature in the Little Colorado River.

Table 1. Parameter Estimates and AIC Statistics for the Temperature-Independent (TIGM) and Temperature-Dependent (TDGM) Growth Models

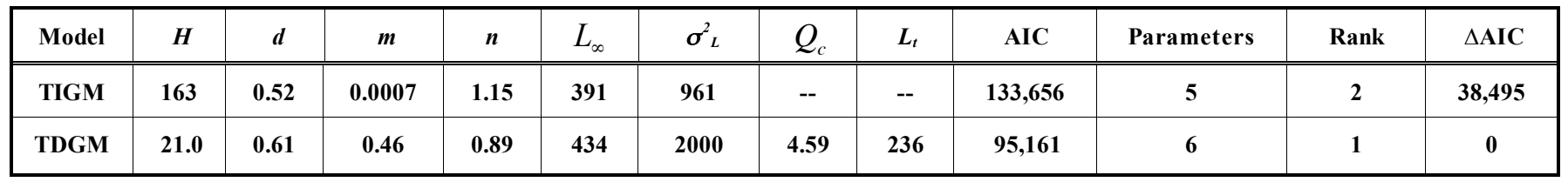

\section{RESULTS}

We fit both the TIGM and TDGM growth models to 14,971 observed growth increments extracted from the humpback chub mark-recapture database. All fish were larger than $150 \mathrm{~mm}$ TL and the time interval between capture and recapture exceeded 30 days. We fit the TIGM with prior variance weighting terms on the $d$ and $n$ parameters $\lambda=\{0.00001,0.0001,0.001,0.01,0.1,0.5,1$, and 10$\}$ to explore the effect of constraining these parameters to values near standard von Bertalanffy values. The log-likelihood was nearly identical for all values of $\lambda=0.01$ and greater, but reducing $\lambda$ below 0.01 caused large changes in the loglikelihood. Therefore, we specified $\lambda=0.01$ as the weighting value for both the TIGM and TDGM. To estimate the parameters of the TDGM, we first had to fit the time-dependent LCR water temperature model. Fortunately, the sine curve function with parameters $t_{\text {peak }}=-0.011, T_{\text {ave }}=17.9$, and $T_{\max }=23.2$ provided good fit to the average monthly temperatures (Fig. 2).

The estimated parameters, and AIC statistics for the TIGM and TDGM are presented in Table 1. The parameter values for the TIGM suggest that anabolism scales as 0.52 mass and catabolism scales as 1.15 mass. These values are different than assumed by the standard von Bertalanffy model and also result in an average $L_{\infty}$ value that is smaller than would be predicted from simple inspection of the data. In contrast, the estimated scaling parameters $(d=0.61$ and $n=0.89$ ) for the TDGM are not much different than what would be expected under the standard von Bertalanffy model where the anabolic scaling parameter $(d)$ should be close to $2 / 3$ and the catabolic scaling parameter $(n)$ should be close to unity. AIC results show strong support for the TDGM over the TIGM (Table 1). However, the parameter correlation matrices for each of these models show very high correlation (Table 2 and Table 3), indicating that all of the parameters are not separately estimable. In situations such as this where the model is not full rank, it has been shown that the AIC is undefined $[36,37]$ suggesting that the AIC criteria may not be appropriate for this comparison.

An alternative way to arbitrate among these two models is to simply graphically examine the model fit to the data. The measured growth rate as a function TL at the start of the interval is extremely variable, particularly at smaller sizes (Fig. 3). This variability is not surprising considering that the rate is measured as a difference between two imprecise length measurements and, for most measurements, expanded 
Table 2. Parameter Correlation Matrix for the TemperatureIndependent Growth Model

\begin{tabular}{|c|c|c|c|c|}
\hline & $H$ & $d$ & $m$ & $n$ \\
\hline \hline$H$ & 1 & & & \\
\hline$d$ & -0.99 & 1 & & \\
\hline$m$ & -0.66 & 0.73 & 1 & 1 \\
\hline$n$ & 0.62 & -0.72 & -0.99 & 0.38 \\
\hline$\sigma_{L}^{2}$ & 0.14 & -0.19 & -0.38 & \\
\hline
\end{tabular}

by a standard von Bertalanffy model, though the TDGM fits are reasonably linear through the portion of the predicted curves populated with data. The temperature-independent model is somewhat of a compromise between the temperature-dependent summer fit and the temperature-dependent winter fit.

Each of the models was used to predict length as a function of age. In addition to the two models fit above, we also predicted length-at-age using the growth function reported in the USFWS recovery goals document [10] and length-at-age using the TDGM for a constant temperature of $10^{\circ} \mathrm{C}$

Table 3. Parameter Correlation Matrix for the Temperature-Dependent Growth Model

\begin{tabular}{|c|c|c|c|c|c|}
\hline & $\boldsymbol{H}$ & $d$ & $m$ & $n$ & $Q_{c}$ \\
\hline $\boldsymbol{H}$ & 1 & & & & \\
\hline$m$ & 0.88 & 0.94 & 1 & & \\
\hline$n$ & -0.86 & -0.93 & -0.99 & 1 & \\
\hline $\boldsymbol{L}_{t}$ & 0.55 & 0.16 & 0.35 & -0.34 & -0.46 \\
\hline
\end{tabular}

by dividing by a short time increment. It is also apparent that all three curves differ from a strict linear relationship implied
(Fig. 4). This last curve is equivalent to a fish experiencing a constant $10^{\circ} \mathrm{C}$ temperature and is a prediction of length-at-

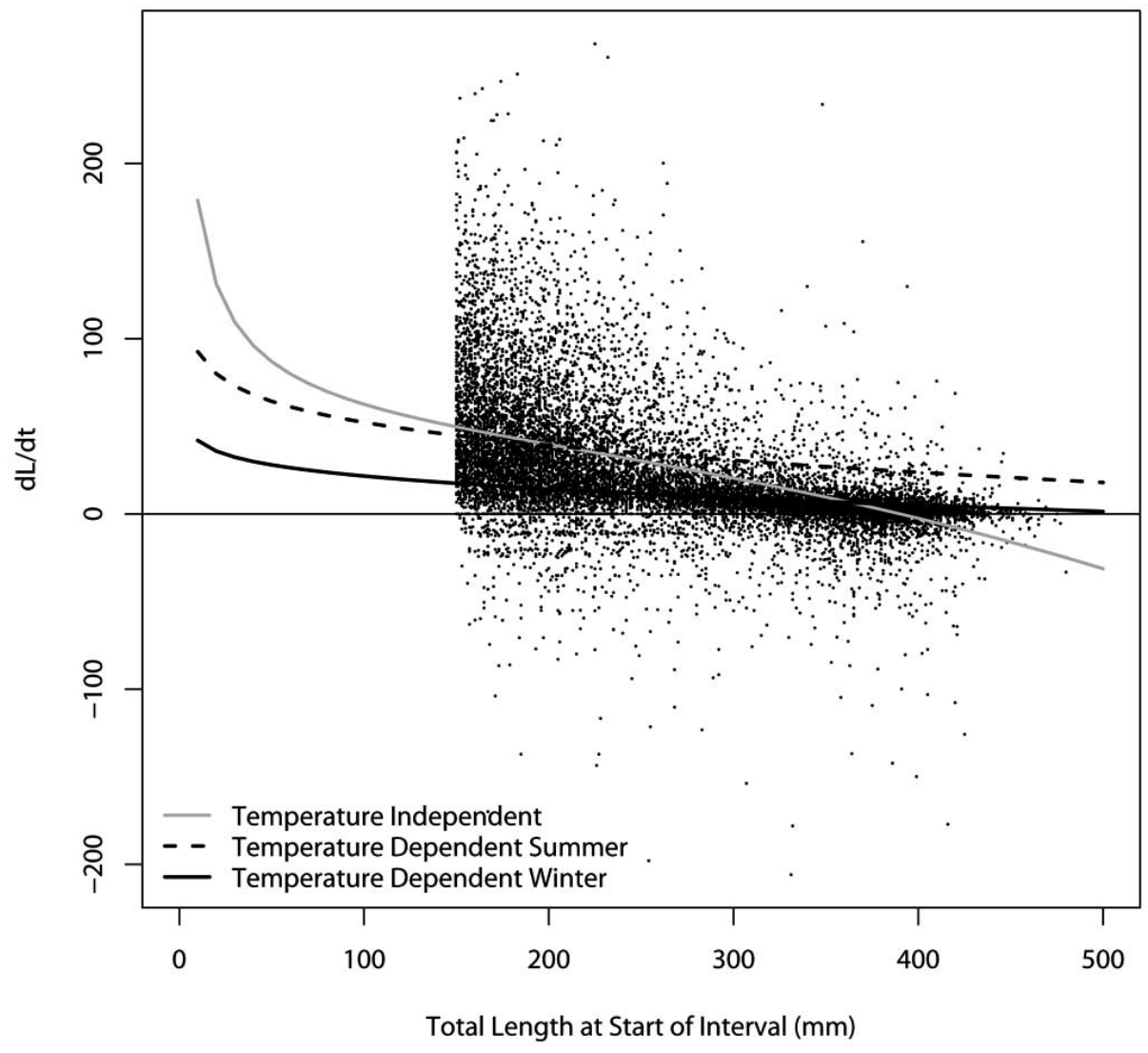

Fig. (3). Observed and predicted humpback chub growth rate (dL/dt) from the temperature-independent growth model and the temperaturedependent growth model during summer and winter. 


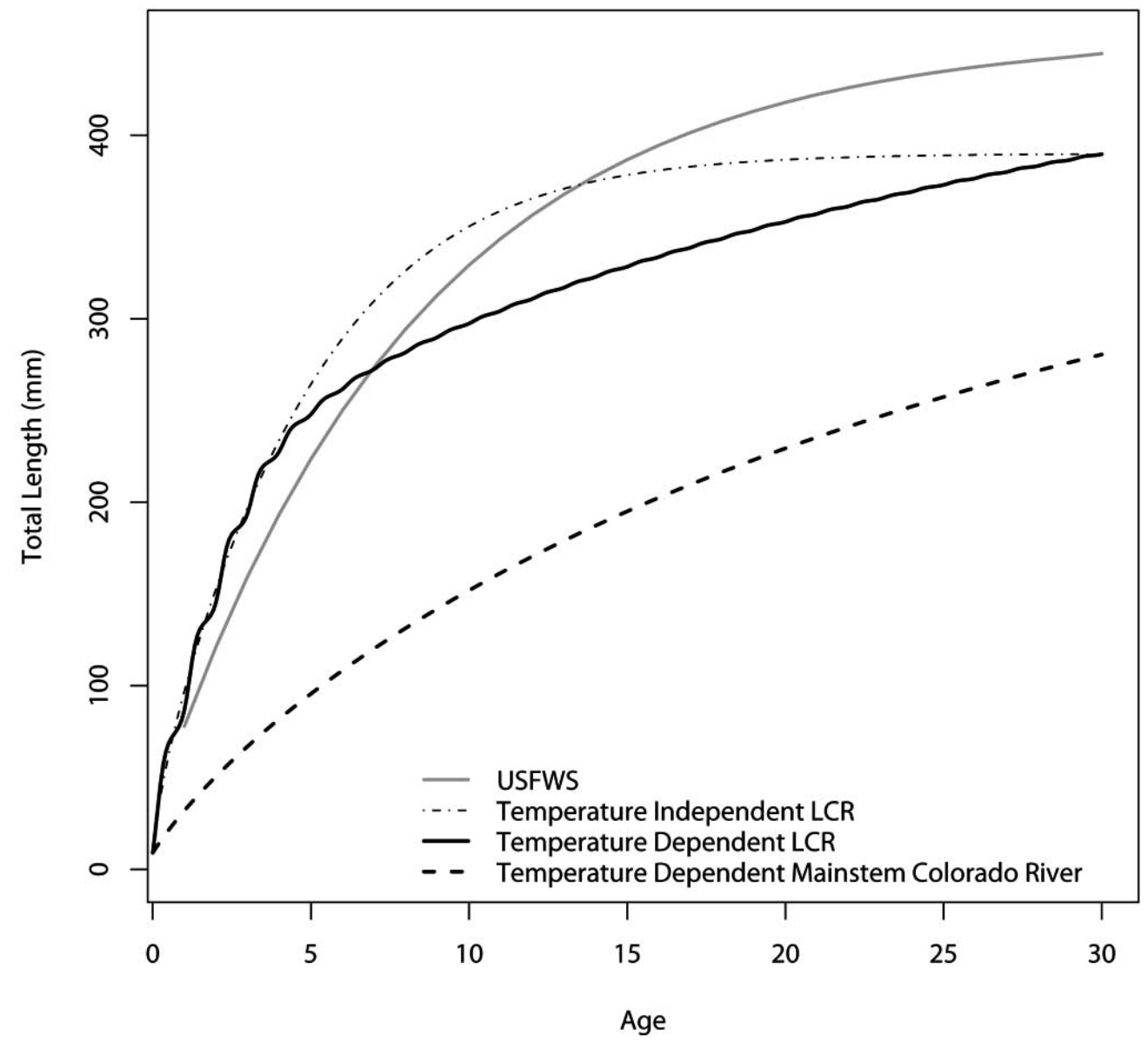

Fig. (4). Predicted humpback chub length-at-age from the U.S. Fish and Wildlife Service (USFWS) growth curve, the temperatureindependent growth model, the temperature-dependent growth model for the Little Colorado River (LCR) humpback chub population, and the temperature-dependent growth model for humpback chub living in the mainstem Colorado River under a constant temperature of $10^{\circ} \mathrm{C}$.

age for a fish spending its entire life in the mainstem Colorado River. Examination of these curves show that the USFWS growth curve predicted somewhat smaller sizes at young ages and larger sizes at older ages than is implied by the mark-recapture data. The TIGM and TDGM predict very similar length-at-age through approximately age-5, but subsequently diverge. Two features are apparent from the TDGM predictions: (1) a temperature-dependent periodic change in growth rate at ages younger than about age-5, and (2) an apparent "bend" in the growth curve at approximately age-4 to age-5. This age corresponds to the length at transition $\left(L_{t}\right)$ where humpback chub are rapidly shifting from primarily LCR occupancy to primarily mainstem Colorado River occupancy. An $L_{t}$ value of $236 \mathrm{~mm}$ TL was most strongly supported by the data and the TDGM (Table 1). It is also informative to utilize the TDGM to predict monthly growth increments as a function of TL. We plotted growth rate predictions from both the LCR population and a population that is experiencing constant $10^{\circ} \mathrm{C}$ temperatures (Fig. 5). This latter curve is presented as a prediction of monthly growth rates that would be observed in the mainstem Colorado River.

The TDGM and Lorenzen [34] mortality relationship were used to predict length-at-age and survivorship from age-1 to age-10 (S10) assuming Colorado River water temperatures of $10^{\circ} \mathrm{C}, 11^{\circ} \mathrm{C}, 13^{\circ} \mathrm{C}$, and $15^{\circ} \mathrm{C}$ (Fig. 6). The TDGM predicts rapid increases in length-at-age with increases in Colorado River water temperature. Additionally and given the relationship between length and mortality assumed here, increases in temperature could result in large $(\sim 3 \mathrm{x})$ increases in survivorship.

\section{DISCUSSION}

Growth model parameter estimation is typically accomplished using paired observations of individual fish age and length [15]. Obtaining this information often requires sacrificing the animal so that calcareous structures may be examined to determine age. The TIGM and TDGM seek to obtain this information through non-lethal sampling using information that is frequently collected in routine mark-recapture studies. Particularly for endangered species such as the humpback chub, a non-lethal method to obtain information on growth is mandatory.

This study addresses the effect of temperature on humpback chub growth and attempts to estimate the length at which fish transition from primarily LCR occupancy to primarily mainstem Colorado River occupancy. The general 


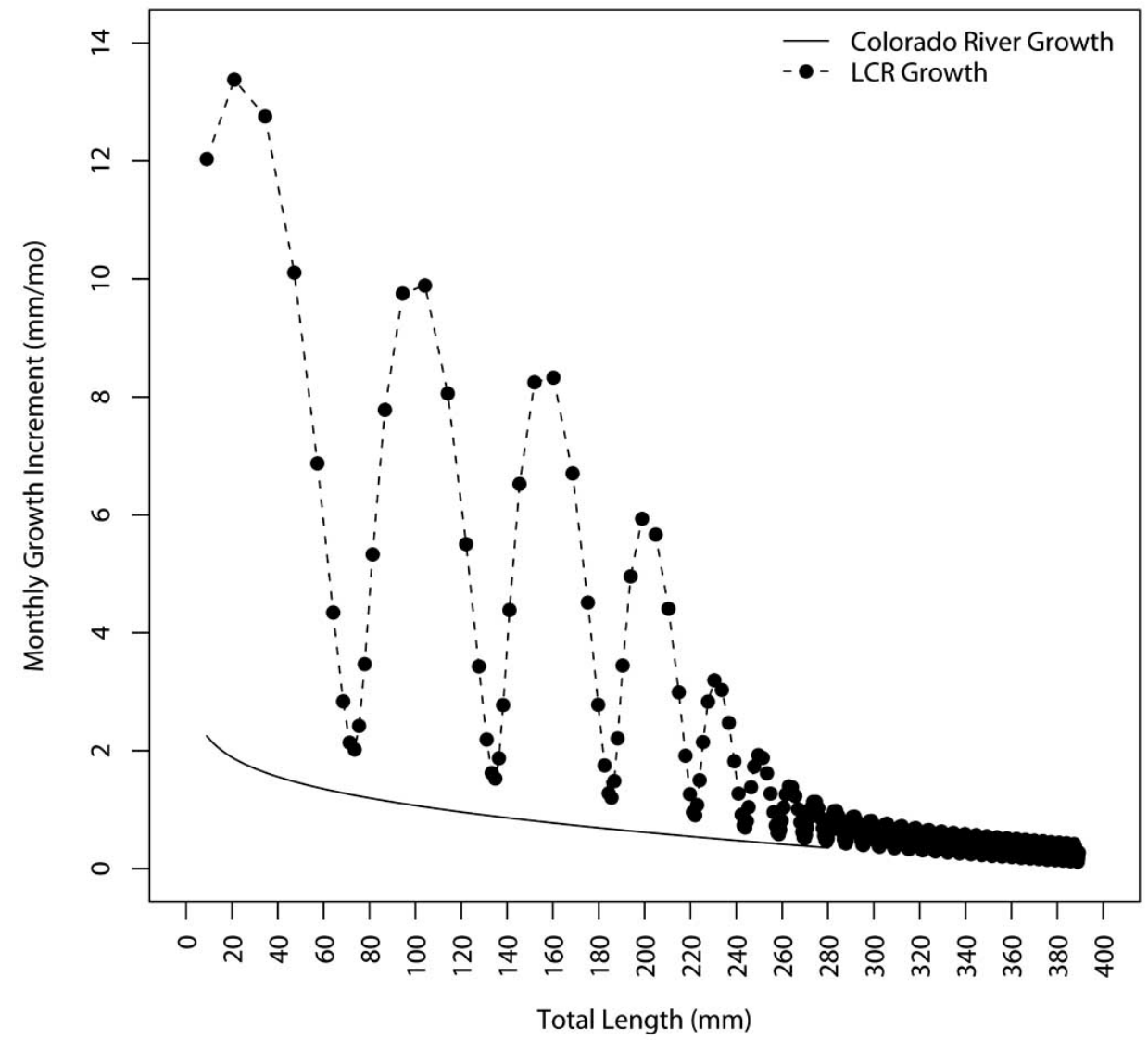

Fig. (5). Predicted monthly growth rate from the temperature-dependent growth model for the Little Colorado River (LCR) population of humpback chub and for humpback chub living in the mainstem Colorado River under a constant temperature of $10^{\circ} \mathrm{C}$.

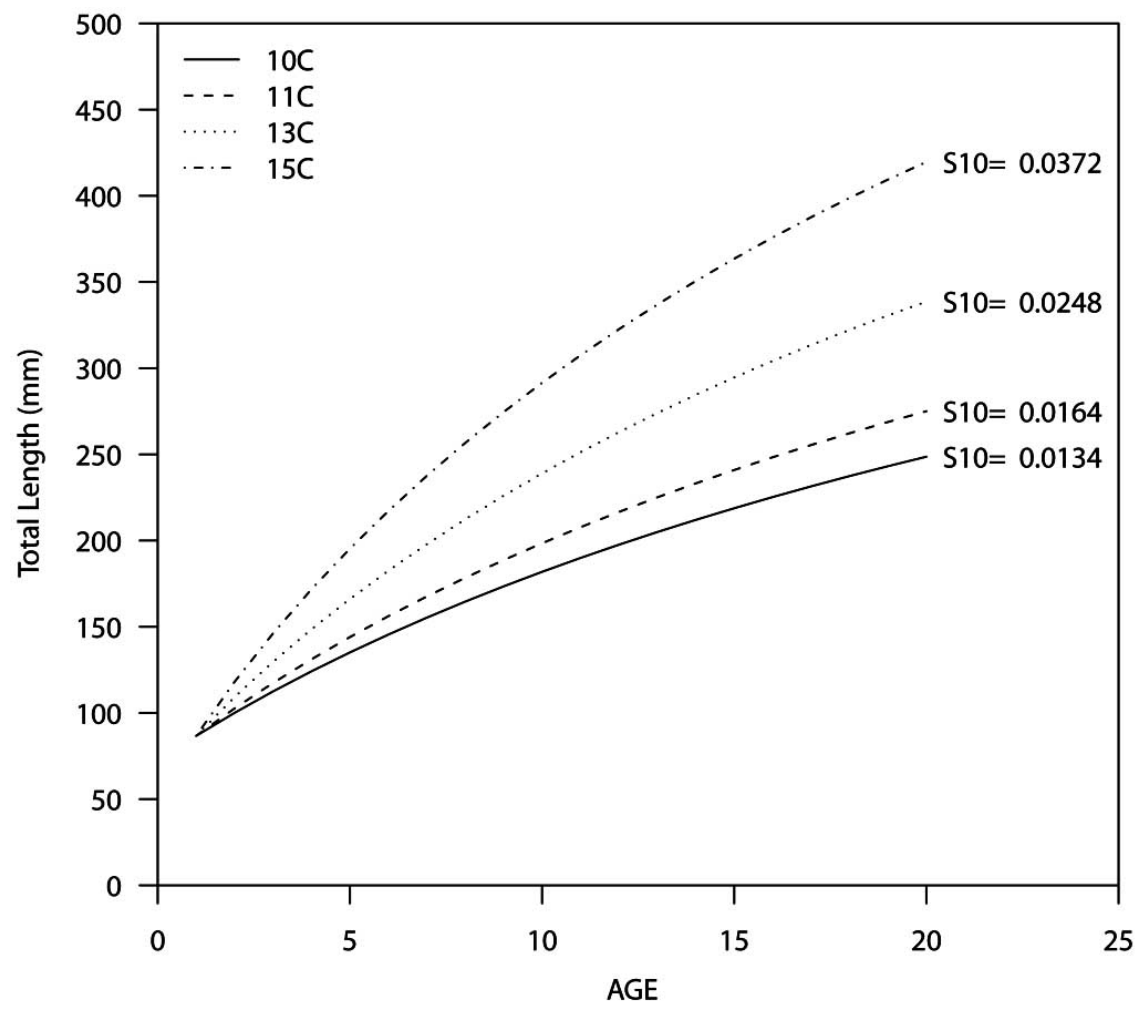

Fig. (6). Predicted total length-at-age and survivorship from age-1 to age-10 (S10) for humpback chub rearing and growing in the mainstem Colorado River with temperatures as indicated in the legend. 
implication from these findings is that growth rate will increase substantially with a temperature increase from $10^{\circ} \mathrm{C}$ to $20^{\circ} \mathrm{C}$ as indicated by the values of $Q_{c}=4.6$ and $Q_{m}=2.0$. These coefficients suggest that anabolism will more than double relative to catabolism across this temperature range. However, Petersen and Paukert [38] constructed a bioenergetics model for juvenile humpback chub and found $Q_{c} \approx Q_{m} \approx 2.4$ suggesting much less potential for increased growth with increased temperature. Though some of the difference in estimated $Q_{c}$ between our analysis and that of Petersen and Paukert [38] may be related to the highly correlated parameters in the TDGM (i.e., may be able to obtain nearly as good a fit with lower $Q_{c}$ and higher $H, d$, and $m$ ), it is also likely that laboratory observations of growth rates may not accurately represent field conditions [39]. In particular, the field estimate of $Q_{c}$ represents not only physiological (laboratory) constraints on feeding, but also effects of any seasonal variations in food availability that are positively correlated with temperature (e.g., insect emergence during spring and summer).

In their study of reproductive ecology of humpback chub in the LCR, Gorman and Stone [13] conclude that adult fish demonstrate a potadromous migration between the mainstem Colorado River and the LCR to spawn. Based on catch rates of humpback chub within the LCR, they suggest that fish larger than $300 \mathrm{~mm}$ TL remain in the LCR only long enough to complete spawning activity. They also report that catch rate of fish between 200-300 mm TL declined by only half following the spawning period. The implication is that fish between 200-300 mm TL may occupy the LCR for longer periods of time than fish larger than $300 \mathrm{~mm} \mathrm{TL}$. The TDGM estimate of $L_{t}(236 \mathrm{~mm}$ TL) is in agreement with these observations suggesting that fish greater than $236 \mathrm{~mm}$ TL should predominantly reside in the mainstem Colorado River.

An alternative hypothesis causing the "kink" in humpback chub growth is onset of maturation and diversion of energy to gamete production [12, 40]. While decreases in skeletal growth following maturation almost certainly occur with humpback chub, maturation typically occurs at approximately the size fish begin to migrate between the Colorado and Little Colorado Rivers [13]. Therefore, it does not appear possible to separate the relative influence of temperature versus changes in energy allocation following maturation [12]. However, numerous studies have documented a correlation between temperature and humpback chub growth preceding maturation [25,27], so it is plausible that this effect continues following maturation. Additionally and as reported by Walters and Essington [12], observed growth increments for mature fish observed in summer under elevated water temperatures are greater than those observed under decreased water temperatures during winter.

A frequently considered management action to benefit Grand Canyon native fishes is to increase Colorado River water temperature by retrofitting Glen Canyon Dam with a selective withdrawal device [41]. Such a device would be constructed on the face of the dam to entrain warmer water from higher elevations within the upstream reservoir. Our results suggest that modest increases in water temperature could result in much faster growth and the potential for greater survival for fish rearing in the mainstem Colorado River. However, it is critical to recognize that these model predictions should not be interpreted as firm expectations, but rather to indicate a general trend for this species only and not for undesirable ecosystem responses to increased water temperature, such as expansion of non-native warmwater species.

This case history should be useful to those studying humpback chub and other endangered species with sampling restrictions seeking to estimate the relationship between fish age and size using non-lethal techniques. This technique shows considerable promise to extract useful information on fish growth from field data, rather than laboratory studies where such information is typically obtained.

\section{ACKNOWLEDGEMENTS}

We would like to thank M. Allen, T. Frazer, C. Walters and C. Staudhammer for comments on an earlier version of this manuscript. We would also like to thank the Grand Canyon Monitoring and Research Center, the University of Florida, and the U.S. Geological Survey-Florida Cooperative Fish and Wildlife Research Unit for financial, logistical, and administrative support. Finally, we would like to acknowledge the many fisheries professionals who have studied Grand Canyon humpback chub and contributed to the database used in this study. Any use of trade names is for descriptive purposes only and does not imply endorsement of the U. S. Government.

\section{REFERENCES}

[1] Pauly D. On the interrelationships between natural mortality, growth parameters, and mean environmental temperature in 175 fish stocks. J Cons Explor Mer 1980; 39: 175-92.

[2] Beverton RJH. Patterns of reproductive strategy parameters in some marine teleost fishes. J Fish Biol 1992; 41: 137-160.

[3] Jensen AL. Beverton and holt life history invariants result from optimal trade-off of reproduction and survival. Can J Fish Aquat Sci 1996; 53: 820-2.

[4] Walters CJ, Martell SJD. Fisheries ecology and management. Princeton: Princeton University Press 2004.

[5] Kimura DK, Chikuni S. Mixtures of empirical distributions: an iterative application of the age-length key. Biometrics 1987; 43: 23-35.

[6] Ricker WE. Computation and interpretation of biological statistics of fish populations. Bull Fish Res Board Can 1975; 191: 1-382.

[7] Devries DR, Frie RV. Determination of age and growth. In: Murphy. BR, Willis DW, Eds. Fisheries techniques, $2^{\text {nd }}$ ed. Bethesda, Maryland, American Fisheries Society 1996; pp. 483-512.

[8] Minckley WL. Native fishes of the Grand Canyon region: an obituary? In: Marzolf GR, Ed. Colorado River Ecology and Dam Management. Washington, DC: National Academy Press 1991; pp. 12477 .

[9] Coggins LG, Pine WE, Walters CJ, Van Haverbeke DR, Ward D, Johnstone HC. Abundance trends and status of the Little Colorado River population of humpback chub. N Am J Fish Manage 2006; 26: $233-45$.

[10] USFWS (U.S. Fish and Wildlife Service). Humpback chub (Gila cypha) Recovery Goals: amendment and supplementation to the humpback chub Recovery Plan. U.S. Fish and Wildlife Service, Mountain-Prairie Region (6). Denver, Colorado 2002.

[11] Kitchell JF, Grimes C, Lindley ST, Otis D, Schwarz C. Report to the adaptive management work group. Glen Canyon Dam Adaptive Management Program: an independent review of ongoing and proposed scientific methods to assess the status and trends of the 
Grand Canyon population of the humpback chub Gila cypha. Final report submitted to the Grand Canyon Monitoring and Research Center, Flagstaff, Arizona 2003.

[12] Walters C, Essington TE. Recovery of bioenergetics parameters from information on growth: overview of an approach based on statistical analysis of tagging and size-at-age data. Open Fish J 2010; 3: 52-68.

[13] Gorman OT, Stone DM. Ecology of spawning humpback chub (Gila cypha) in the Little Colorado River near Grand Canyon, Arizona. Environ Biol Fish 1999; 55: 115-33.

[14] Fabens AJ. Properties and fitting of the von Bertalanffy growth curve. Growth 1965; 29: 265-89.

[15] Quinn IITJ, Deriso RB. Quantitative Fish Dynamics. New York: Oxford University Press 1999

[16] Sainsbury KJ. Effect of individual variability on the von Bertalanffy growth equation. Can J Fish Aquat Sci 1980; 37: 241-7.

[17] Kirkwood GP, Somers IF. Growth of two species of Tiger Prawn, Penaeus esculentus and P. semisulcatus, in the Western Gulf of Carpentaria. Aust J Mar Fresh Res 1984; 35: 703-12.

[18] Francis RICC. Are growth parameters estimated from tagging and age-length data comparable? Can J Fish Aquat Sci 1988; 45: 93642.

[19] James IR. Estimation of von Bertalanffy growth curve parameters from recapture data. Biometrics 1991; 47: 1519-30.

[20] Wang YG, Thomas MR, Somers IF. A maximum-likelihood approach for estimating growth from tag-recapture data. Can J Fish Aquat Sci 1995; 52: 252-9.

[21] Laslett GM, Eveson JP, Polacheck T. A flexible maximum likelihood approach for fitting growth curves to tag-recapture data. Can J Fish Aquat Sci 2002; 59: 976-86.

[22] Paloheimo JE, Dickie LM. Food and growth of fishes. I. A growth curve derived from experimental data. J Fish Res Board Can 1965; 22: 521-42.

[23] Essington TE, Kitchell JF, Walters CJ. The von Bertalanffy growth function, bioenergetics, and the consumption rates of fish. Can $\mathrm{J}$ Fish Aquat Sci 2001; 58: 2129-38.

[24] Valdez RA, Ryel RJ. Life history and ecology of the humpback chub (Gila cypha) in the Colorado River. Arizona Final Report, Contract No. 0-CS-40-09110, Salt Lake City, UT 1995.

[25] Robinson AT, Childs MR. Juvenile growth of native fishes in the Little Colorado River and in a thermally modified portion of the Colorado River. N Am J Fish Manage 2001; 21: 809-15.
[26] Paloheimo JE, Dickie LM. Food and growth of fishes. II. Effects of food and temperature on the relation between metabolism and body weight. J Fish Res Board Can 1966; 23: 869-908.

[27] Clarkson RW, Childs MR. Temperature effects of hypolimnialrelease dams on early life stages of Colorado River big-river fishes. Copeia 2000; 2: 402-12.

[28] Voichick N, Wright, SA. Water-temperature for the Colorado River and tributaries between Glen Canyon Dam and Spencer Canyon, Northern Arizona 1988-2005. USGS, Reston, Virginia, US Geological Data Series 2007; No. 251.

[29] Ladson L, Allan W. Solver. Frontline Systems. Incline Village: NV 2002

[30] Fournier, D. AD Model Builder. Otter Research, Sidney, British Columbia, Canada 2000

[31] Clarke A, Johnston NM. Scaling of metabolic rate with body mass and temperature in teleost fish. J Anim Ecol 1999; 68: 893-905.

[32] Martell S, Walters CJ. University of British Columbia, personal communication, 2008.

[33] Burnham KP, Andersen DR. Model selection and multimodel inference. A practical information-theoretic approach, 2nd ed. New York: Springer Science + Business Media 2002.

[34] Lorenzen K. Allometry of natural mortality as a basis for assessing optimal release size in fish-stocking programmes. Can J Fish Aquat Sci 2000; 57: 2374-81.

[35] Coggins LG. Abundance trends and status of the Little Colorado River population of humpback chub; an update considering 19892006 data: U.S. Geological Survey Open-File Report 2007; No. 1402.

[36] Viallefont A, Lebreton JD, Reboulet AM. Parameter identifiably and model selection in capture-recapture models: a numerical approach. Biometric J 1998; 40: 313-25.

[37] Bozdogan H. Akaike's information criterion and recent developments in information complexity. J Math Psychol 2000; 44: 62-91.

[38] Petersen JH, Paukert CP. Development of a bioenergetics model for humpback chub and evaluation of water temperature changes in the Grand Canyon, Colorado River. J Am Fish Soc 2005; 134: 96074.

[39] Rice JA, Cochran PA. Independent evaluation of a bioenergetics model for largemouth bass. Ecology 1984; 65: 732-9.

[40] Quince C, Abrams PA, Shuter BJ, Lester NP. Biphasic growth in fish I: theoretical foundations. J Theor Biol 2008; 254(2): 197-206.

[41] GCMRC (Grand Canyon Monitoring and Research Center). USGS workshop on scientific aspects of a long-term experimental plan for Glen Canyon Dam, April 10-11, 2007, Flagstaff, Arizona: U.S. Geological Survey Open-File Report 2008; No. 1153

(C) Coggins and Pine; Licensee Bentham Open

This is an open access article licensed under the terms of the Creative Commons Attribution Non-Commercial License (http://creativecommons.org/licenses/by-nc/3.0/) which permits unrestricted, non-commercial use, distribution and reproduction in any medium, provided the work is properly cited. 